\title{
Global Activity of Ian Donald Ultrasound Education
}

\section{Ritsuko K Pooh, Asim Kurjak}

\begin{abstract}
Ultrasound examination is completely different from other imaging modalities such as MRI or CT in terms of real-time imaging and interpretation. Examiners are requested to have both interpretation capacity and scanning expertise simultaneously based on physiological and pathological knowledge of maternal fetal medicine. Therefore, ultrasound examination needs appropriate education and training. Ian Donald Inter-University School of Medical UItrasound is one of successful global educational systems in ultrasound education in Obstetrics and Gynecology. The number of its branches has been growing more than 80 countries. It contains basic courses, fellowship program, distance learning. Undoubtedly, Donald Schools have to reinvent themselves in order to remain attractive to the younger generation, as well as stay success story in globalized medicine.
\end{abstract}

Keywords: Ian Donald, Ultrasound, Education.

How to cite this article: Pooh RK, Kurjak A. Global Activity of Ian Donald Ultrasound Education. Donald School J Ultrasound Obstet G ynecol 2013;7(3):323-328.

\section{Source of support $\mathrm{Nil}$}

Conflict of interest: None declared

\section{INTRODUCTION}

With the rapid development of information and communication technologies, industrial nations are transforming into societies in which knowledge is the most contested and valuable good - and the need for continuing education is even more important. A t present, creativity and ingenuity comprise at least $50 \%$ of the value-added chain. Just a few decades ago, the value of a machine tool was determined in large part by its material value and the cost of producing it. Today these factors account for only some $20 \%$, while the biggest portion of the share consists of development, software, design and downstream servicesthat is, in value-added factors with high knowledge intensity. $\mathrm{K}$ nowledge has become the decisive factor for any institution competing globally. Do globalization and the enormous acceleration of social, economic, and political transformation process demand a different kind of education? It is clear that education is the most important investment in the national economy. A nyone who does not invest in education is left behind.

Learning means change, new modes of behavior, new structures, unfamiliar situations and creativity. The increased speed at which we have to acquire new knowledge, insights, and abilities is forcing us to divide learning into novel, shorter phases. The traditional choreography of learning with its long, rigidly defined school, job, and university educational periods, is already obsolete. Selforganized, lifelong learning is becoming a necessity. Education is needed more than ever to give the individual the proper orientation to make good judgments. Only on this basis can he or she think and act self-sufficiently, selfconfidently and self-effectively.

\section{Ultrasound Education}

Ultrasound imaging diagnosis has an important role in obstetrics and gynecology. Recently prenatal imaging modality includes magnetic resonance imaging (M RI) and three-dimensional computed tomography (3D-CT) as well as ultrasound. M RI and CT require capacity of postimaging radiographic image interpretation. U Itrasound examination is, however, completely different from other imaging modalities in terms of real-time imaging and interpretation. Examiners are requested to have both interpretation capacity and scanning expertize simultaneously based on physiological and pathological knowledge of maternal fetal medicine. Therefore, ultrasound examination needs appropriate education and training. Fetal ultrasound education/training, however, is not systematic and very few successful educational programs are provided. It is not easy to establish ultrasound education curriculum, because ultrasound education should include case examples/video cases, interactive tutorials, onlineultrasound simulation, onsite attendance necessary for practical experience, on-site ultrasound simulation, hands-on training of scanning patients. The good training is, needless to say, to look at how to scan on clinical scene and try to scan than to look at sophisticated images taken by experts. It is not the same as the education of the other imaging such as how to read M R I and CT. Ultrasound much depends on examiners' skill as well as reading images. Important thing is how to screen, how to detect, and how to demonstrate the most objective and informative images.

\section{Ian Donald Inter-University School of Medical Ultrasound}

Ian D onald (1910-1987) has changed the face of obstetrics and gynecology by the invention of diagnostic ultrasound, in the middle of the 20th century more than any others have done. It is not overstating the fact to say that this innovation 
has changed the way of thinking of our generation. In recognition of his most significant contribution to the overall development of diagnostic ultrasound, a School of M edical Ultrasound named after Ian Donald was formed in Dubrovnik, Croatia in 1981 and at present, it has 80 branches in countries of whole world. B ranches of Ian Donald InterUniversity School of M edical U Itrasound have each national director (Fig. 1).

\section{Objectives of Ian Donald School are:}

1. To promote:

- The science and art of ultrasound scanning

- Research and education in the field of medical ultrasound

- Continuous training in ultrasound

- Facilitation and dissemination of information featured in scientific publications, including the Ian Donald School J ournal of Ultrasound in Obstetrics and Gynecology

- Appropriate counseling of women who receive ultrasound examinations.

2. To provide expert advice to those entering the field of ultrasound.

3. To increase knowledge of methodology for implementing recent ultrasound advances.

4. To contribute to the improvement of teaching standards by the introduction of computer technology and devices for tel emedicine.

\section{The Basic Course}

Concrete educational program includes basic ultrasound education (basic theory and basic practice), advanced ultrasound education (advanced diagnostic imaging) and

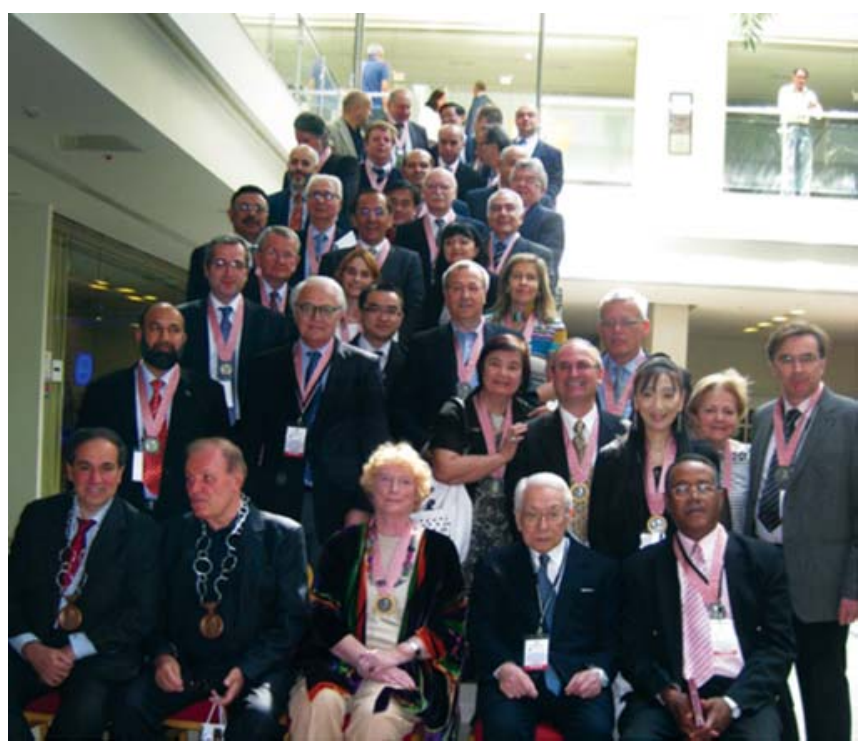

Fig. 1: Ian Donald School Directors at the Global Congress in Dubrovnik, Croatia, celebrating the 30th anniversary of the school fellowship ultrasound education (individual clinical practice). Basic theory includes theory of ultrasound, knowledge of basic science (anatomy, physiology), knowledge of basic art (symmetry, 3 dimension) and study of sophisticated images, and it follows by basic practice including live scan demo (Figs 2 and 3), hands-on (Fig. 4) and case studies (Fig. 5). The contents of the basic course are as below:

- Gestational age assessment

- Ultrasound examination in normal pregnancy

- Color Doppler

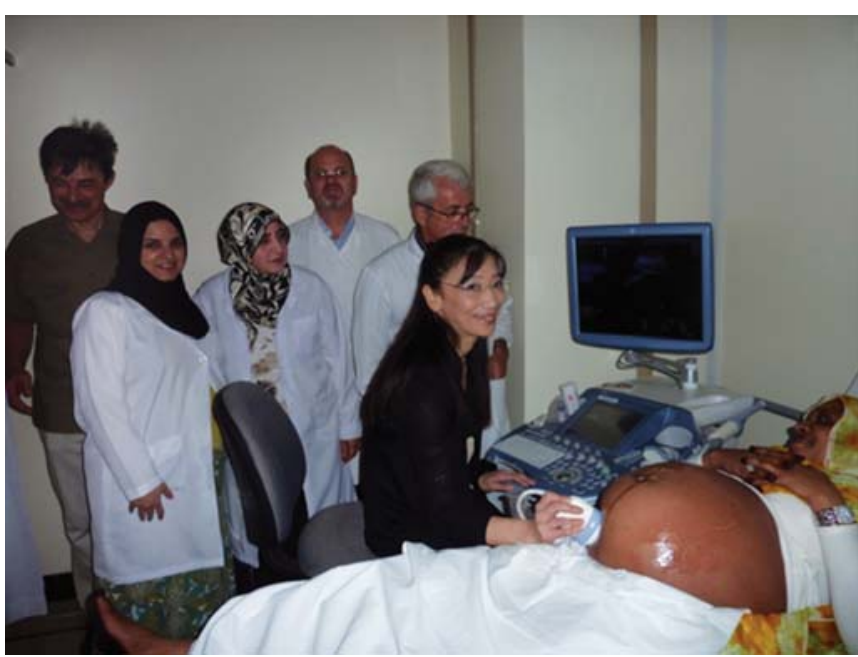

Fig. 2: Live scan demonstration of transabdominal fetal scan

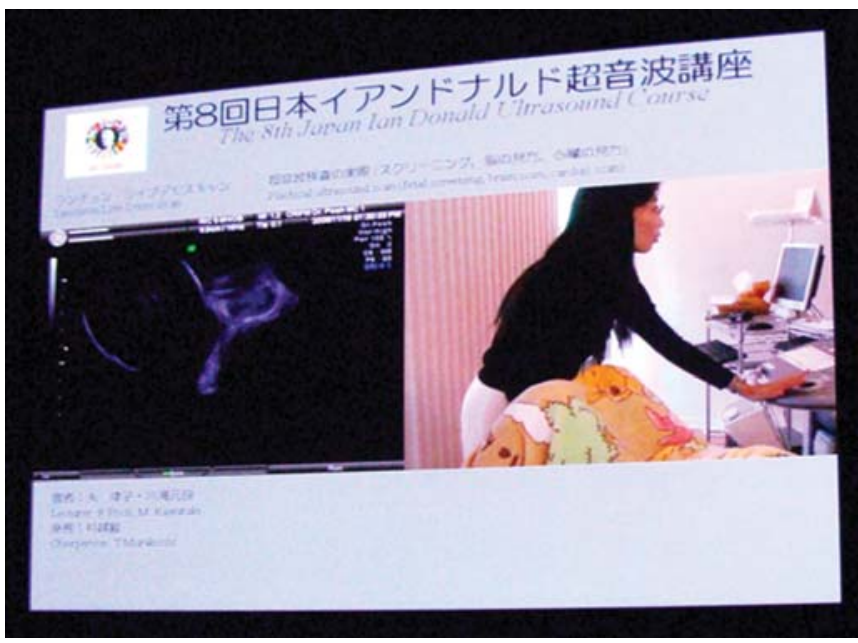

Fig. 3: Live scan demonstration of transvaginal fetal brain scan
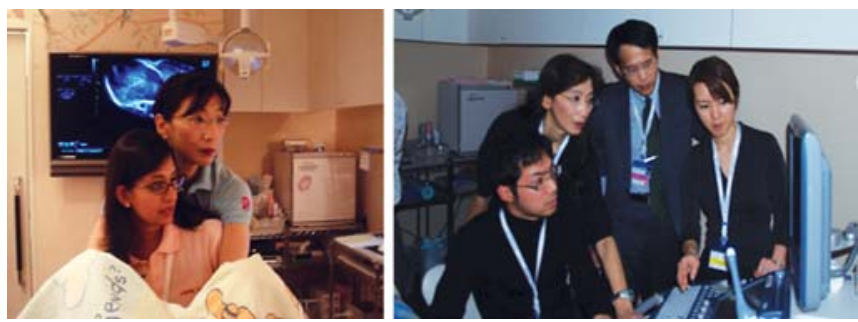

Fig. 4: Hands-on training of transvaginal fetal brain scan (left) and transabdominal fetal scan (right) 


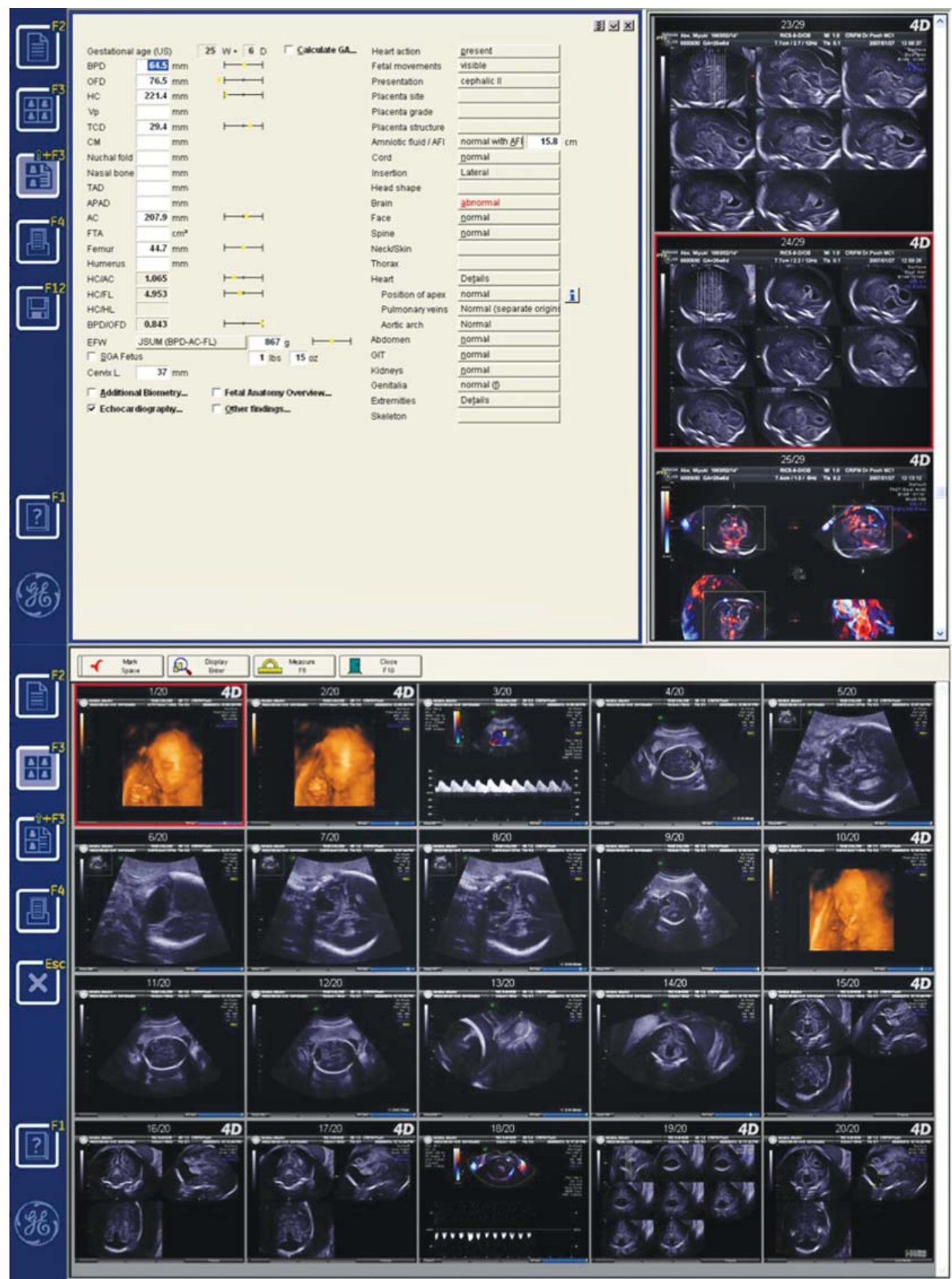

Fig. 5: Case conference study by using image database system

- Transvaginal sonography

- Normal embryonal and early fetal anatomy

- Ultrasonic assessment of early placentation

- Ultrasonic markers of chromosomopaties

- Pathology of placenta

- Ultrasonic assessment of normal and abnormal fetal growth

- Ultrasound in preterm delivery

- Multiple pregnancy
- Fetal echocardiography

- Prenatal diagnosis

- Counseling a woman when an anomaly is diagnosed

- Prenatal screening in the first and second trimester

- Color Doppler in early pregnancy

- Hemodynamic of embryo

- U teroplacental hemodynamic and intervillous blood flow

- Color Doppler in late pregnancy, arterial blood flow

- Transvaginal examination: PID and benign processes 
- The assessment of malignant pelvic processes

- Ectopic pregnancy

- Congenital anomalies: CNS, neck, thorax and abdomen, urinary tract, skeletal abnormalities

- Endometriosis

- Ultrasound in the assessment of female infertility

- Uterine anomaly and hysterosonosalpingography.

\section{The Fellowship Program}

Dubrovnik International U niversity specialized fellowship study on ultrasound in obstetrics and gynecology. Thestudy consists of 6 obligatory and 1 elective modules with total of 300 hours and 44.9 ECTS. Fellowship programs are 1 year courses on a part-time basis. The unique opportunity is that these courses can be attended without compromising professional or private commitments because they are organized as six modules, over the time of 12 months, every 2nd month, for 9 days including 2 weekends. U pon passing all the prescribed examinations and fulfilling all the course requirements, attendants are aw arded $M$ aster degree issued by Dubrovnik International U niversity. They are eligible to continue PhD study at the same U niversity. The attendants are those with a diploma of completed education, residents or specialists of $\mathrm{Ob} / \mathrm{G}$ yn license. A fter finishing this program the participants should be capable of:

- Knowing how to use and adjust and being oriented with images produced by transabdominal and transvaginal ultrasound.

- Identifying and differentiating between normal and abnormal gynecological ultrasound examination.

- Identifying different pathology on pelvic ultrasound.

- Performing complete ultrasound examination in all trimesters of pregnancy.

- Learning how to write a comprehensive obstetric ultrasound report in the 1st, 2nd and 3rd trimesters of pregnancy.

- Performing a 1st trimester ultrasound scan.

- Performing a complete fetal anatomy scan in 2nd trimester of pregnancy.

- Recognizing fetal dysmorphology and knowing the significance of their presence.

- Assessing fetal well-being.

- Knowing how and when to use color Doppler in Ob/Gyn Ultrasound.

- Witnessing and getting acquainted by the invasive procedures in fetal medicine.

- Witnessing and being acquainted for the 3D/4D ultrasound application in obstetrics and gynecology.
The duration of the fellowship program is 1 academic year. It includes 6 modules covering the whole spectrum of ultrasound in $\mathrm{Ob} / \mathrm{G} y n$ and 1 elective module. Each module is delivered in a week (5 working days). The attendance is on part time basis, i.e. the candidate should free him/herself to complete each module separately. Schedule includes one module every 2 months ( 7 days of education every 2 months). Each trainee should complete 6 modules before being subjected to examination. Each module is composed of the theoretical part and practical training (scanning demonstration and hands-on training which is almost $40 \%$ of the curriculum). Each module delivers 50 hours of training including the theoretical and practical part. Total number of hours allocated is 300 hours. Each candidate is expected to complete his/her log book and present it at the end of each module. A comprehensive end of module exam will be given at the end of each module. A fter completion of each module, the fellow should present or send via e-mail the certificate proving attendance, which qualifies $\mathrm{him} / \mathrm{her}$ to take the summative (final) exam. Final exam includes ultrasound skills exam, written essay and theoretical oral exam with committee of three examiners. Detailed structure of the fellow ship program is divided into 7 modules:

- Module 1: Ultrasound in gynecology

- Module 2: Ultrasound in the 1st trimester

- Module 3: Fetal well being (fetal biometry and fetal growth)

- M odule 4: Fetal anatomy-placenta-umbilical cord

- Module 5: Fetal congenital anomalies

- Module 6: 3D and Doppler in gynecology and infertility

- Module 7: How to write scientific texts-elective module. Registration for the fellowship through direct application to DIU or online through the website: www.iandonald school.org. The website will include all the required information. Fellowship in ultrasound in obstetrics and gynecology, performed in Welcare Hospital in Dubai, is now in its 4th year. Lectures are given by international top level faculty, and extensive ultrasound hands-on under supervision of Prof. Ulrich Honemeyer and Dr A mira Talic provides sufficient practical experience. $H$ ands-on is provided in groups of five participants each, at three work stations equipped with high end ultrasound machines (V oluson expert, V oluson E8). The fifth master course will start on 1st of M arch 2013 with maximum 15 participants. International faculty are A sim Kurjak (Croatia), Frank A. Chervenak (USA), Roberto Romero (USA), Sanja K upesic (USA ), E berhard M erz (Germany), A ris A ntsaklis (G reece), I vica Zalud (USA), Guillermo A zumendi (Spain), Giovanni 
M onni (Italy), Ritsuko Pooh (J apan), B iserka Funduk K urjak (Croatia), M ilan Stanojevic (Croatia), UIrich Honemeyer (UAE), and many more. Thirty-four candidates have al ready successfully graduated as $M$ asters in ultrasound in obstetrics and gynecology. They received their $M$ aster diplomas in Dubrovnik in the unique ambiance of Dubrovnik International University.

\section{Distance Learning}

The distance learning proposed by Sanja Plavsic K upesic in 2009 aims to establish a distinct visual identity for Ian Donald School and to unify all its various branches and entities into a single voice. It seeks to engage, inspire curiosity and raise awareness about the Ian Donald School and supports its continued grow th, giving it higher visibility and hel ping people everywhere to understand its work and its future goals. In general, distance learning is reflecting a universal human need to learn and understand the world around them. In our new virtual school the campus will be virtual-students will be able to attend classes from around the world. The Ian Donald School will be administered through a plexus of real-time information arteries. Campus activities and class sessions will be monitored to gauge educator performance and student learning progress. Advanced ultrasound technologies will be immersed into the learning process. It will certainly help to develop a 'lifelong learning way of life'.

The aims of distance learning are to create a financially self-sustaining program that meets the needs of a wide range of adult learners in $\mathrm{Ob} / \mathrm{G}$ yn ultrasound by:

- Reviewing and identifying effective forms of technology-assisted lifelong learning in the field of ultrasound
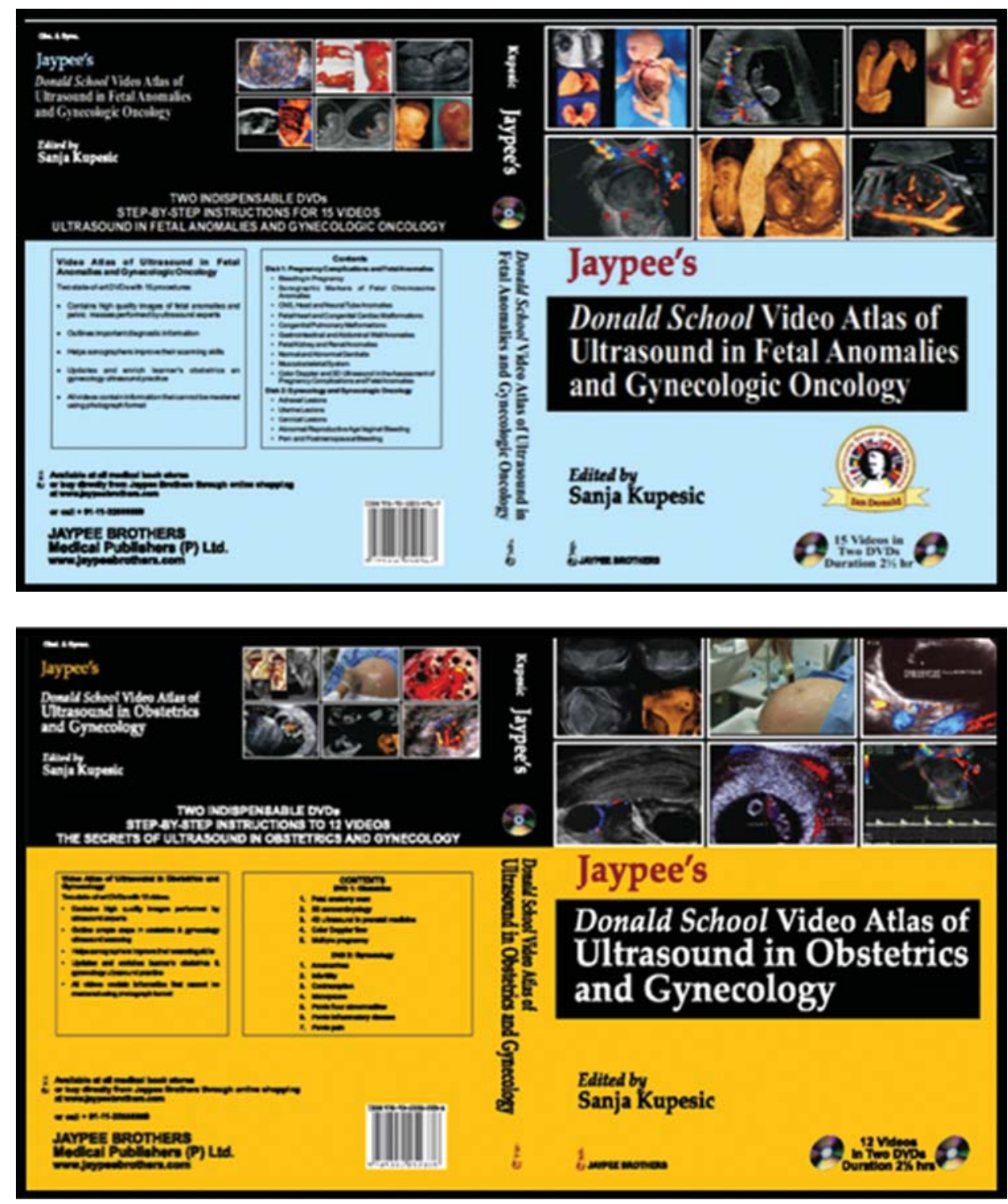

Fig. 6: E-books of Donald School Video Atlas 


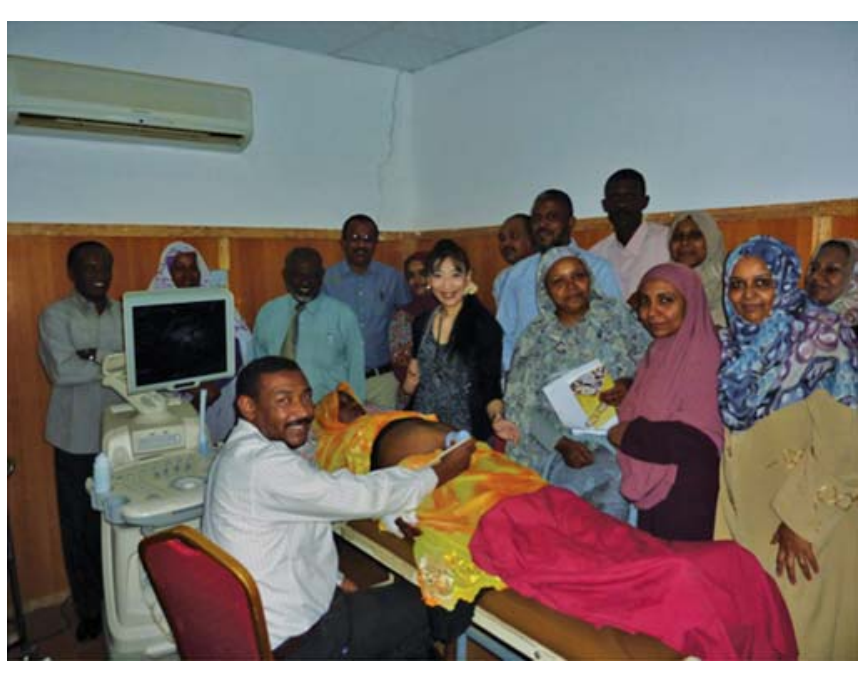

Fig. 7: Hands-on training of transabdominal fetal scan in Khartoum, Sudan

- Conducting applied research into technology-assisted lifelong learning

- Developing course frameworks, courses and educational services that exploit technology in support of lifelong learning

- Evaluating all work undertaken and disseminating the outputs and insights gained to international audiences. With distant learning we are creating a constructive, open forum for Donald School students that do not usually have a chance to interact, to create innovative, appropriate, current solutions for the changing needs of diagnostic ultrasound in the global community. Professor K upesic and her team, and all of national school directors will contribute to monitoring current and future challenges and their impact on education in a comprehensive manner on a global scale through highlighting and expanding innovative approaches to major education challenges. They will help develop strategies to establish new and enduring educational patterns, initiating actions and concrete solutions to rise to the 21 st century global challenges, and acquiring the ability to anticipate the future challenges. Figure 6 shows e-books utilized for distance learning.

\section{Ultrasound Education in Developing Countries}

$M$ any of developing countries succeed in establishing Ian Donald course (Fig. 7). Our role is to encourage them to continue and to encourage the rest of developing countries.

\section{The Future Perspective on Global Activity}

A most important factor which has influenced the changes occurring in education has been the installation and development of the internet and electronic multimedia techniques. Traditional education as well as contemporary education is supported by informatics technologies in a unique system of flexible education. In order to use the advantages of flexible education, it is necessary to combine different forms of learning.

Indeed, Donald Schools have to reinvent themselves in order to remain relevant to the current generation. The focus in an I an D onald School is on knowledge augmentation and not on grades. Great learners are the product of great educators. It is hoped that I an D onald School educators will be true, dedicated 'human amplifiers,' turning education into a memorable experience. In our newly formed fellowship program, upon graduation, student laureates will earn a specialized diploma of ultrasound in obstetrics and gynecology, with a leadership position in the work place. This is done in the belief that education must be driven by innovative thinking, adaptability, and worldwide collaboration. Wherever thinking happens, ideas follow, know ledge grows, and people discover new ways to unlock their potential. Although in its infancy, the fellowship program has blossomed with its wide acceptability. Undoubtedly, Donald Schools have to reinvent themselves in order to remain attractive to the younger generation, as well as stay success story in globalized medicine. W ith this innovation we sincerely hope that our school will stay as an internationally recognized brand, representing the future of education as it faces new global challenges and the changing needs of future generations of first class ultrasonic experts.

We hope to identify opportunities to shape a global educational vision for the 21st century under the theme of Donald School distance learning. The future is built on the past. The Ian Donald School has a remarkable past. It is important that teachers and students stay as futuristically thinking scientists and teachers. In a knowledge society, where competitive edge is directly tied to innovation, the Ian Donald School has to move forward.

\section{ABOUT THE AUTHORS}

\section{Ritsuko K Pooh}

Director, CRIFM Clinical R esearch Institute of F etal M edicine PM C Osaka, Japan; Professor, D epartment of Human Science, Dubrovnik International University, Dubrovnik, Croatia; Executive Director A sian R egional Director, J apanese B ranch Director, I an D onal d InterUniversity School of M edical U Itrasound, Dubrovnik, Croatia

Correspondence Address: CRIFM PM C, 7-3-7, U ehommachi, Tennoji, Osaka \#543-0001, Japan, e-mail: rkpooh@me.com

\section{Asim Kurjak}

Rector, Dubrovnik International University, Dubrovnik, Croatia; School Director, Ian Donald Inter-University School of Medical Ultrasound, Dubrovnik, Croatia 